\title{
Historical perspectives on the diagnosis and treatment of trigeminal neuralgia
}

\author{
Chad D. Cole, M.Sc., James K. Liu, M.D., and Ronald I. Apfelbaum, M.D. \\ Department of Neurosurgery, University of Utah School of Medicine, Salt Lake City, Utah
}

\begin{abstract}
Since the earliest recorded history of medicine, physicians have been challenged by the difficulty in relieving the great pain experienced by individuals suffering from trigeminal neuralgia (TN). The nature of the pain and the events that incite it have been well described, but effective treatments with acceptable levels of side effects remained elusive until the latter part of the 20th century. As a result, many theories about the origins of TN have been proposed, along with numerous treatment modalities. The pathophysiological causes of TN remain incompletely understood, but the medical and surgical treatment techniques currently used offer effective ways to relieve this extremely painful condition. In this historical review the authors discuss the initial descriptions of tic douloureux, Fothergill disease, and TN, along with various therapeutic interventions and their refinements.
\end{abstract}

\section{KEY WORDS • trigeminal neuralgia - tic douloureux $・$ historical overview}

\section{OVERVIEW}

\section{Trigeminal Neuralgia as a Clinical Entity}

Trigeminal neuralgia, also known as tic douloureux or Fothergill disease, is a clinical syndrome distinguished by brief paroxysms of unilateral, lancinating facial pain that is characteristically triggered by cutaneous stimuli, such as a breeze on the face, chewing, talking, or brushing the teeth., ${ }^{3,4}$ ${ }^{38}$ Many of those who are affected experience multiple attacks daily, and, although they are free of pain between attacks, they live in constant fear of recurrences. ${ }^{38}$ The mysterious nature of this disease confused the early development of treatment, because the origin remained elusive. Nevertheless, a review of the history of TN indicates that innovative observations made by discerning clinicians resulted in methods that were at least partially successful in alleviating the pain of this disease, despite the limited understanding of its exact pathogenesis.

Aretaeus of Cappodocia provided one of the earliest descriptions of migraine headache in the second century, and his description has also been credited as the first account of TN. ${ }^{50,51,59}$ As Stookey and Ransohoff ${ }^{59}$ relate, in his chapter "Cephalaea," Aretaeus made no clear distinction between symptoms that represented a migraine headache and those that represented TN. Approximately 900 years later (AD 1037), as recounted by Ameli, ${ }^{1}$ Avicenna described two facial syndromes; one was characterized by "a disease in which the face is pulled unnaturally, its normal shape is distorted and the natural ability of both lips meeting is inhibited." This clearly was a description of facial palsy, but the

Abbreviations used in this paper: MVD = microvascular decompression; TN = trigeminal neuralgia. second case included pain that had a throbbing, tearing, and stabbing nature, characteristics consistent with TN.

The first clear description of TN that was not confused with another disease entity was made in 1688 by Drs. Johannes Michael Fehr and Elias Schmidt, secretaries of the Imperial Leopoldian Academy of Natural Sciences..$^{59}$ In their eulogy of Johannes Laurentius Bausch, they vividly described the painful symptoms that had plagued the distinguished founder of their Academy for the 4 years prior to his death. Bausch was said to have experienced a sharp, shooting pain in his right maxilla that came on suddenly like a bolt of lightening, varying in intensity, leaving him unable to speak or eat solid food. ${ }^{59}$ In the fall of 1665 , the pain disappeared, only to return early that same winter. The pain that Bausch subsequently experienced was so intense that it forced him to remain bedridden. He eventually died of malnutrition because his dietary intake was limited by the excruciating pain. ${ }^{19}$

John Locke, a physician and well-known philosopher, provided the first full description of $\mathrm{TN}$ by a medical practitioner, along with an account of its treatment. In 1677, while in Paris, Locke was called in to evaluate the wife of the English ambassador, the Countess of Northumberland, who was suffering from excruciating pain in the face and lower jaw. ${ }^{37,52}$ Locke deliberated whether to prescribe "opening medicine" (laxative therapy), because of the wintry weather at the time. In spite of the cold and the inconvenience he would cause his patient, he eventually overcame his reluctance and thoroughly purged the Countess. Her pain improved several weeks later. ${ }^{59}$

Nearly a century after that, two prominent clinical accounts were reported, one by Nicolas André (Fig. 1A) and 
one by John Fothergill (Fig. 1B) that further characterized this disease entity. In 1756, André reported two cases of TN, which he termed tic douloureux. ${ }^{2,14,52} \mathrm{He}$ conceptualized the disease in terms of convulsions, and he believed that true tonic convulsions, tetanus, and spasm clinique belonged in a single disease spectrum. The term tic douloureux was used to imply contortions and grimaces accompanied by violent and unbearable pain. André believed that the cause was "vicious nervous liquids" that distressed the nerve and caused painful shocks. Using this reasoning, he followed the proposal of Maréchal (a contemporary surgeon) by applying caustic substances to the infraorbital nerve at the infraorbital foramen over a period of days until the nerve was destroyed. ${ }^{43,59}$

In 1773, John Fothergill, an English physician, presented 14 cases of a painful affliction of the face.$^{20}$ His description of TN has been considered an accurate and clear account. ${ }^{59}$ In Fothergill's description he made the following comments:

The affection seems to be peculiar to persons advancing in years, and to women more than to men.... The pain comes suddenly and is excruciating; it lasts but a short time, perhaps a quarter or half a minute, and then goes off; it returns at irregular intervals, sometimes in half an hour, sometimes there are two or three repetitions in a few minutes.... Eating will bring it on some persons. Talking, or the least motion of the muscles of the face affects others; the gentlest touch of a hand or a handkerchief will sometimes bring on the pain, whilst a strong pressure on the part has no effect. ${ }^{20}$

Fothergill asserted that TN was not within the spectrum of a convulsive disorder. Instead, he postulated that this disease might be the manifestation of some type of cancer; he found a hard tumor of the breast in two of the 14 cases he presented. Given his meticulous description of the clinical symptoms, many thereafter referred to this condition as "Fothergill's disease." 43,59

Thus, although a clear description of this distinctive condition had been made by the end of the 18th century, it was

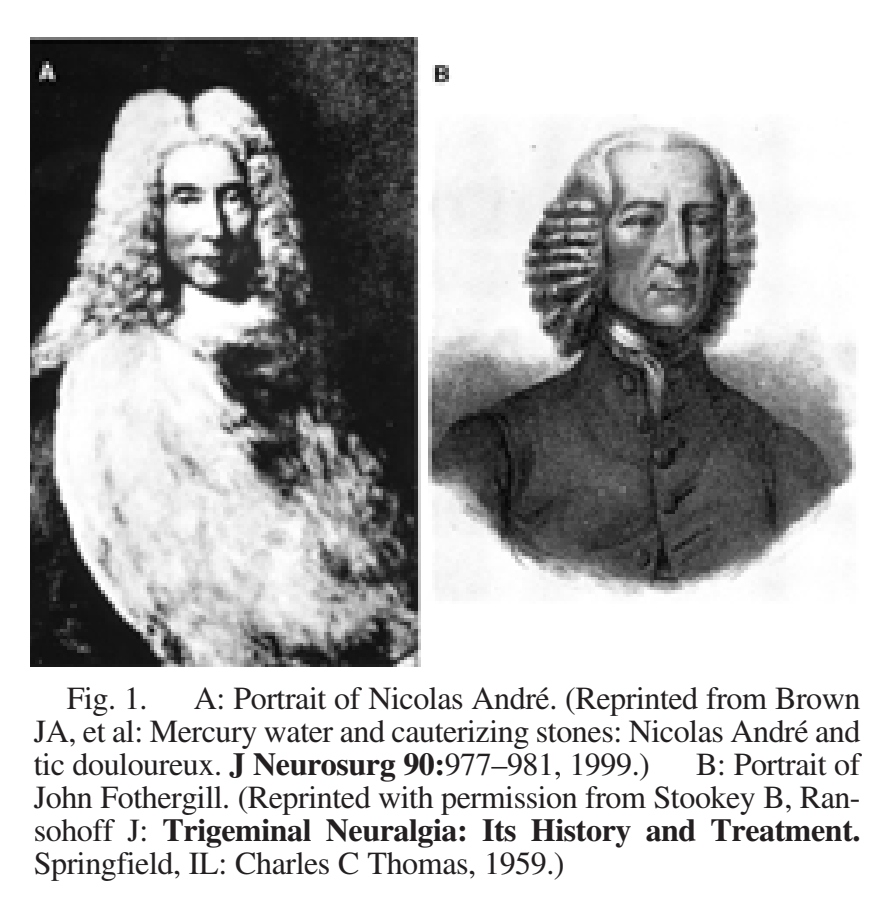

not until the 1820s, when Charles Bell established the separate functions of the trigeminal and facial nerves, that tic douloureux and Fothergill disease would be truly differentiated from other conditions. ${ }^{67}$ Bell's contribution enabled tic douloureux to be localized to the trigeminal nerve, which ultimately led to the evolution of the name of the disease to trigeminal neuralgia.

\section{EVOLUTION OF THERAPIES FOR TN}

Because of the lack of understanding of the disease, early treatments prescribed for TN were haphazard. ${ }^{56,65}$ Tooth extraction was often tried because the pain frequently involved the mandibular or maxillary area of the mouth. Other historical approaches included hot baths, rest in a dark room, and ingestion of wine. ${ }^{66}$ Near the turn of the 20th century, medical therapy, chemoneurolysis, rhizotomy, manipulations of the trigeminal nerve, and radiation therapy were promulgated as possible treatments for providing relief of this painful condition. Since the 1960 s, percutaneous ablative procedures and MVD have proven to be reliable and acceptable surgical treatments for TN. More recently, stereotactic radiosurgery has been advocated as well.

\section{Medical Treatment}

Early Medicines. In 1773, Fothergill suggested the bark of the cinchona tree (also known as Peruvian bark) for the treatment of TN. ${ }^{20,59}$ Quinine is the chief alkaloid agent found in this bark, and this agent has analgesic effects on the central nervous system. In 1820 , Hutchinson ${ }^{29}$ provided an extensive review of the medical treatments offered at the time; these included the following: “... blistering, purging, pills of conium maculatum [sic], muriate of mercury, camphorated mercurial ointment, ether, opium and arsenic in gruel." In 1874, Sawyer and Mackey ${ }^{59}$ recommended powder of gelsemium soaked in a pint of spirits. This treatment was thought to be effective if it caused the patient to experience symptoms such as loss of sight, double vision, headaches, or paralysis.

Trichloroethylene. In 1915, Plessner ${ }^{59}$ reported the acute toxic manifestations of trichloroethylene, a sweet-smelling, white liquid that was used widely in Germany during World War I for removing grease from machinery. The toxic manifestations included vertigo, vomiting, swelling of the optic disc, and bilateral loss of sensation in the distribution of the trigeminal nerve with sparing of the motor root. ${ }^{59}$ Learning of Plessner's original presentation, Oppenheim suggested that his colleague use this agent for treating TN, and in 1918 Plessner reported a series of 17 patients who were treated with inhalations of trichloroethylene for this disease. ${ }^{59}$ All patients experienced improvement in their pain with no facial anesthesia. This treatment was, however, not without side effects. Later investigators reported adverse effects including nausea, transient unconsciousness, ventricular tachycardia, and cardiac arrest. ${ }^{59}$

Stilbamidine. In 1942, Napier and Sen Gupta described bilateral trigeminal neuropathy that occurred 2 to 5 months after administration of stilbamidine in patients with kala azar. $^{41}$ In 1955, Woodhall and Odom ${ }^{68}$ reported their experience with 41 patients who were treated with stilbamidine for TN. These patients were given a 10-day course of intravenous stilbamidine and did not experience lasting pain relief until 40 to 150 days later. Adverse effects of this treat- 
ment included bilateral facial numbness, paresthesias, itching, burning, tingling, and watering of the eyes, and irreversible hepatic and renal damage if the drug or the patient was exposed to ultraviolet light. ${ }^{41,59}$

Anticonvulsant Agents. The use of anticonvulsant agents as a possible treatment modality for TN was first introduced by Bergouignan ${ }^{11}$ in 1942, when he reported the use of sodium diphenylhydantoin. ${ }^{66} \mathrm{He}$ believed that the episodic nature of TN was similar to that of epilepsy. Other hydantoin preparations were subsequently tried and phenytoin was widely used until 1962 , when Blom ${ }^{12}$ demonstrated greater efficacy with carbamazepine in controlling TN. This remains the drug of choice today in the medical treatment of TN, because it controls the pain in approximately $90 \%$ of patients. ${ }^{38}$

Oxcarbazepine, a derivative of carbamazepine, is a newer drug that is reported to have similar clinical effectiveness but fewer side effects than carbamazepine. Several other medications, most of which are anticonvulsant agents, have also been used as ancillary drugs and may on occasion provide a measure of control, either alone or in conjunction with carbamazepine or phenytoin. These include clonazepam, lamotrigine, and valproic acid. ${ }^{15,58,66}$ In general, these drugs have not been as effective as carbamazepine, oxcarbazepine, or phenytoin. ${ }^{38}$ More recently, gabapentin has been widely promoted for this indication, but there are no published controlled studies supporting this use, and in the senior author's (R.I.A.'s) experience, it has not been effective.

Muscle Relaxants. The use of muscle relaxants for treatment of TN was proposed by King in $1966 .{ }^{31} \mathrm{He}$ published the results of a 7-year study of 52 consecutive patients treated with mephenesin carbamate, a centrally acting skeletal muscle relaxant. ${ }^{66}$ Although he found that this medication offered some benefit, it was never widely adopted. More recently, baclofen, a $\gamma$-aminobutyric acid agonist, has been shown to be somewhat effective in the treatment of TN ${ }^{21,38}$ Follow-up reports of the use of baclofen in patients with TN have indicated that there may be a synergism between this agent and carbamazepine or phenytoin. 8,38

Carbamazepine. In the senior author's experience with several thousand patients with TN, carbamazepine is the most effective medication, initially controlling the pain in approximately $90 \%$ of cases. This drug must be started at a low dose and the dose escalated slowly to avoid side effects that can limit its use. If such side effects occur, phenytoin is the second-best drug, helping approximately $50 \%$ of patients. It may also be used with carbamazepine to achieve a synergistic effect. The other medications mentioned only help an occasional patient when used alone but may have a role as a secondary drug along with either phenytoin or carbamazepine. The goal of all treatments is to render the patient free of pain and of the fear of recurrent pain. If this cannot be achieved with medications that have an acceptable level of side effects, surgical treatment should be considered.

\section{Percutaneous Surgical Procedures}

Chemoneurolysis. Bartholow (in 1876) and Neuber (in 1883 ) were the first to promote the benefits of chemoneurolysis in the treatment of $\mathrm{TN}^{59}$ Bartholow described the use of chloroform and Neuber of osmic acid; these materials were injected into the vicinity of the nerve trunks. Shortly thereafter, animal experiments performed by Pitres and Vaillard in 1888 demonstrated that both motor and sensory paralysis occurred after injection of alcohol directly into a nerve.$^{59}$ According to Stookey and Ransohoff,, 59 these experiments led to the first reported use of alcohol injection into peripheral nerves in the treatment of TN, by Schloesser in 1904. Many investigators subsequently advocated peripheral alcohol injections in the treatment of $\mathrm{TN}$, even though side effects included temporary weakness of the muscles of mastication, transient sensory loss, and/or paresthesia. ${ }^{59}$ The limitations of this treatment also included the expected eventual recurrence of $\mathrm{TN}$ as the nerve regenerated and sensation returned. ${ }^{66}$

In an effort to provide more permanent pain relief than could be achieved by peripheral injections, attention was turned to the injection of destructive substances into the gasserian ganglion. ${ }^{59}$ In 1907, Wright injected osmic acid into the gasserian ganglion through an operative exposure. ${ }^{59}$ In contrast, Harris, in 1910, performed a percutaneous injection of alcohol directly into the ganglion without a surgical incision. Thirty years later, Harris ${ }^{25}$ published the results of this procedure in 1433 patients in whom he was able to produce complete anesthesia and pain relief. Approximately two thirds of his patient population required a second or third injection before anesthesia was permanent.

Although no deaths were associated with this method of alcohol injection, substantial morbidity was present and included postinjection paresthesia, herpes, hyperesthesia, neuroparalytic keratitis, and unilateral loss of taste, along with the expected paralysis of the muscles of mastication, which lasted approximately 3 months after treatment. ${ }^{59,66}$ Percutaneous insertion of a needle through the foramen ovale via an extraoral approach, a method that is still used today, was originally described by Härtel ${ }^{26}$ in 1914 (Fig. 2). Although alcohol chemoneurolysis involved the aforementioned trigeminal morbidities, the main limitation of alcohol injection into the gasserian ganglion was the possibility of multiple cranial nerve palsies if the agent spread through the cerebrospinal fluid spaces at the base of the brain (Fig. 3).

To overcome the possibility of inadvertently involving multiple cranial nerves during the injection of alcohol into the gasserian ganglion, in 1916 Pollock and Potter ${ }^{47}$ suggested the use of x-ray images to check the position of the needle. This original suggestion came about as a result of findings in cadaver studies, but in 1936 Putnam and Hampton, ${ }^{48}$ and later Kulenkampff ${ }^{59}$ in 1942 reported excellent results when x-ray films were used to verify the position of the needle prior to injection. ${ }^{66}$ To minimize further the adverse consequences of alcohol injection into the gasserian ganglion, Selverstone, in 1955, developed a needle insulated to the tip, through which he passed an electrical current to indicate when the tip was in contact with the nerve (see Stookey and Ransohoff ${ }^{59}$ ).

A more refined type of gasserian ganglion injection, in which glycerol was used, eventually developed by chance. In 1981, during the development of a stereotactic technique for gamma irradiation of the trigeminal ganglion, Häkan$\operatorname{son}^{24}$ used glycerol as a medium to introduce tantalum dust into the trigeminal cistern. The sensory root adjacent to the trigeminal ganglion was marked by the tantalum dust for 


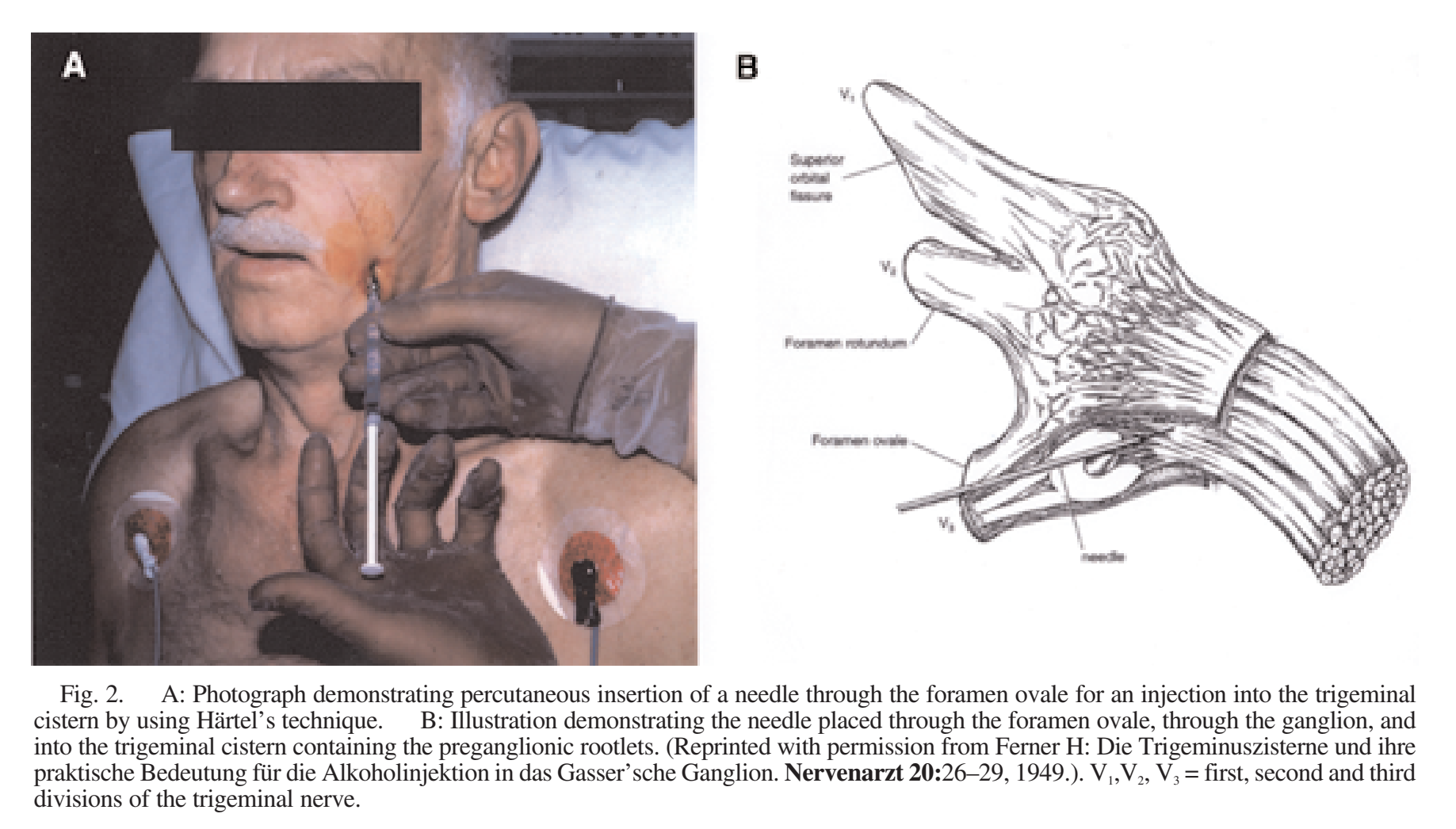

stereotactic targeting. ${ }^{24,66}$ Serendipitously, Häkanson found that the intracisternal injection of glycerol alone completely freed the patient from the paroxysmal pain, thereby introducing percutaneous retrogasserian glycerol chemoneurolysis. All percutaneous procedures yield only temporary relief. The less destructive procedures produce less numbness and fewer dysesthetic sequelae, but the pain tends to recur sooner. This may be a good trade-off, however, because it is easier to repeat the procedure to treat recurrent pain than to treat dysesthesias, which can be very severe at times. In our experience, $75 \%$ of patients treated with glycerol neurolysis obtain at least 3 years of pain relief. ${ }^{39}$

Radiofrequency Lesioning. Electrocoagulation of the trigeminal nerve was attempted by Réthi ${ }^{66}$ in 1913 , soon after peripheral chemoneurolytic injections began to be used. In 1931, Kirschner ${ }^{32}$ described his elaborate operative setup that included a specially designed head frame to guide the insertion of an insulated needle through the foramen ovale to perform electrocoagulation of the gasserian ganglion (see Wilkins ${ }^{66}$ ). In these techniques, monopolar Bovie type current was used for the coagulation. Despite modest technical advances over the next few decades, electrocoagulation therefore continued to have a relatively high complication rate.

In 1974, Sweet and Wepsic ${ }^{60}$ introduced radiofrequencygenerated thermal energy to damage the preganglionic trigeminal rootlets in the Meckel cave. They also integrated the use of short-acting anesthetic agents, electrical stimulation for precise localization, and temperature monitoring to control the lesion delivery more precisely. These adjuncts improved the efficacy and safety of the procedure. ${ }^{38}$ Since the popularization of this technique by Sweet and Wepsic, many neurosurgeons have improved on this approach, permitting partial, precise destruction within the gasserian ganglion and its sensory root. ${ }^{66}$ Nugent $^{42}$ and also Rovit ${ }^{55}$ advocated using a fine cordotomy-type electrode and a neuroleptic anesthetic agent to allow repeated small lesions

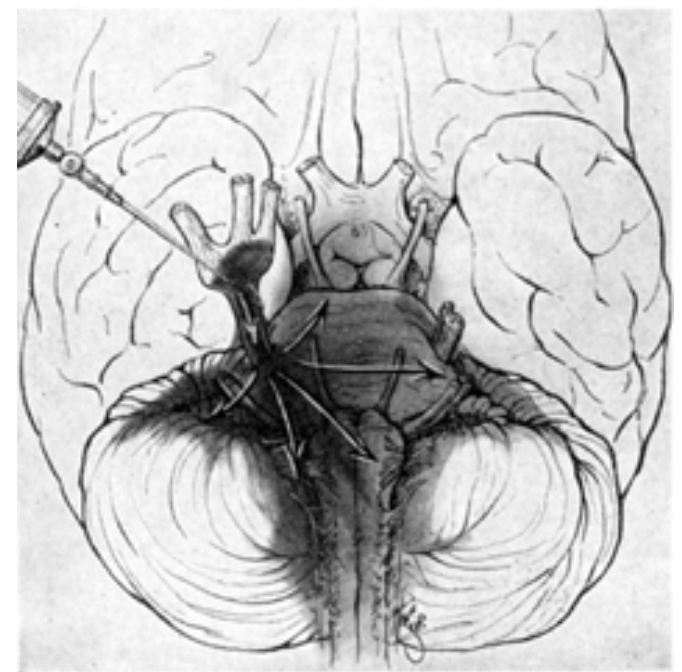

Fig. 3. Drawing demonstrating the main limitation of alcohol injection into the gasserian ganglion. Multiple cranial nerve palsies can occur if the alcohol spreads through the cerebrospinal fluid spaces at the base of the brain (arrows). (Reprinted from Dandy WE: The brain, in Walters W, Ellis FH Jr (eds): Lewis-Walters Practice of Surgery. Hagerstown, MD: W.F. Prior Co., 1963, Vol XII, pp 1-671.) 
to be made while testing the patient to control the lesion size. Tew and Taha ${ }^{62}$ introduced the use of a curved thermistor-tipped electrode that allowed close contact with the involved sensory fibers to allow selective lesioning. With experience, it was recognized that less dense lesions worked equally well. This modification of the technique decreased the incidence of postoperative dysesthesias.

Trigeminal Nerve Compression. In 1952, Taarnh $\varnothing j^{61}$ described decompression of the dorsal root of the trigeminal nerve in the dural canal over the margin of the petrous ridge, whereas Pudenz and Shelden described decompression of the second and third divisions of the trigeminal nerve. ${ }^{59}$ Taarnh $\varnothing j$ reported excellent results after decompressing the posterior part of the gasserian ganglion and the posterior trigeminal root via a subtemporal approach in 10 patients; however, he made no mention of having found the dorsal root compressed or abnormally angulated.

In 1955, Shelden, et al., ${ }^{57}$ reported excellent long-term results among the patients they originally described in 1952 . They showed that the decompression of the maxillary and mandibular divisions at the foramen rotundum and the foramen ovale as well as the dorsal root decompression used by Taarnh øj were effective in relieving the pain of TN. They and others ${ }^{59}$ reasoned that the common denominator between these methods was the operative trauma to the nerve fibers. Thus, nerve compression had its beginnings when Shelden and colleagues began to rub the posterior root just behind the ganglion with the intent to induce a mild trauma that might result in pain relief without causing significant sensory impairment. Subtemporal compression operations were hailed as a success because this method of relieving TN reduced the incidence of sensory loss, keratitis, and paresthesia ${ }^{66}$ This type of treatment was not long lasting, however, and in 1964 Shelden provided a follow-up report showing a $25 \%$ recurrence rate.

The original work of Taarnh $ø j$ and Shelden, et al., provided a basis for Mullan and Lictor, ${ }^{40}$ who introduced the technique of percutaneous balloon compression of the gasserian ganglion in 1983. The goal was to traumatize the trigeminal ganglion and preganglionic rootlets mechanically by using a percutaneously inserted Fogarty balloon catheter. The catheter was threaded through the foramen ovale and into the trigeminal cistern, where the balloon was inflated. Ipsilateral trigeminal motor weakness was common postoperatively but usually resolved within 3 months. In 1996, Brown, et al., ${ }^{13}$ added a refinement to Mullan and Lictor's technique. ${ }^{66}$ They emphasized the use of a blunt stylet following skin penetration to avoid the possibility of vascular injury. Despite the continued experience and refinement of percutaneous balloon compression, severe limitations exist; namely, approximately two thirds of patients experience bradycardia and brief hypotension, $61 \%$ have postoperative numbness, and $16 \%$ experience ipsilateral masseter-pterygoid muscle weakness that resolves within 3 to 12 months.

\section{Open Surgical Procedures}

Nerve Sectioning and Microvascular Decompression. Circa 1750, Maréchal, surgeon to Louis XIV, believed that cutting the infraorbital nerve would relieve painful tics. ${ }^{59} \mathrm{He}$ subscribed to the theories of André, namely that the pain of TN was due to vicious nervous liquids that distressed the nerve and caused painful shocks. Interestingly, the first two patients with TN treated by André had undergone unsuccessful surgeries by Maréchal that were aborted because of extensive hemorrhage. In 1768, Veillard and Dussans made two attempts to sever the infraorbital nerve to relieve the pain of tic douloureux. Their surgical outcomes were not successful in the first two instances, so they elected not to try a third time. ${ }^{59}$

Armed with the understanding that Bell and others had developed regarding the trigeminal and facial nerve distributions and functions, the unsuccessful beginning of surgical intervention for the treatment of $\mathrm{TN}$ was in part overcome by Carnochan in $1858 .{ }^{59}$ Carnochan believed that the gray matter of the gasserian ganglion was a "generator of nervous power of which, like a galvanic battery, it affords a continuous supply; while the branches of the ganglion under the influence of the diseased trunk, serve as conductors of the accumulated nervous sensibility." He therefore approached the ganglion through the maxillary sinus to remove this ganglionic gray matter along with an inch or more of the maxillary branch of the nerve..$^{59}$

Working independently, Drs. Rose of London $(1890)^{53}$ and Andrews of Chicago (1891) ${ }^{59}$ refined Carnochan's theory and developed an operation that consisted of cutting the zygoma and coracoid process along with detaching the masseter and temporal muscles to expose the base of the skull and foramen ovale. Sectioning of the second and third divisions of the trigeminal nerve was performed with a limited craniectomy to expose the gasserian ganglion. This procedure, however, remained unsatisfactory because the ganglion could not be adequately visualized with this approach, which often led to its incomplete removal, along with frequent hemorrhage..$^{59}$

A more satisfactory surgical approach was advocated by Horsley, Taylor, and Colman ${ }^{28}$ in 1891, wherein sectioning of the preganglionic trigeminal rootlets was accomplished via a middle fossa approach. ${ }^{6}$ For this approach, the gasserian ganglion was accessed through the temporal bone, followed by opening of the dura and retraction of the temporal pole. ${ }^{59}$ Complications were encountered in this procedure because attempts to strip the ganglion near the cavernous sinus regularly resulted in tearing of the sinus. Nevertheless, this procedure would become a seminal innovation that others refined, eventually offering a sound surgical alternative in the treatment of TN.

In 1892, Hartley ${ }^{27}$ and Krause ${ }^{34}$ (Fig. 4) independently described an extradural subtemporal approach for gasserian ganglionectomy. ${ }^{54,66}$ Their approach eventually became known as the Hartley-Krause procedure (Fig. 5), and it involved creating a small $\Omega$-shaped incision just above the zygoma and turning down a tissue flap composed of skin, muscle, and bone to expose the ganglion. ${ }^{59}$ The nerves were divided at the foramen ovale and the foramen rotundum and excised to a point back beyond the gasserian ganglion. The Hartley-Krause procedure was refined and popularized by Spiller and Frazier ${ }^{59}$ in 1901. The major contribution of Spiller and Frazier was the implementation of Tiffany's idea of subtotal resection by sparing the upper portion of the ganglion and the first branch of the trigeminal nerve to decrease the risk of corneal anesthesia. ${ }^{59}$

In 1900, Cushing ${ }^{16}$ modified the procedure by using a more basal trajectory to work below the middle meningeal artery as it passed along the basal surface of the dura mater 

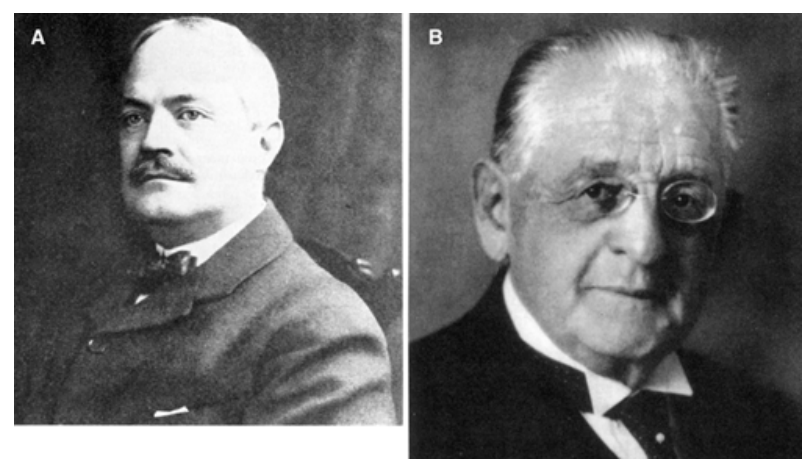

Fig. 4. A: Photograph of Frank Hartley. (Reprinted with permission from Stookey B, Ransohoff J: Trigeminal Neuralgia: Its History and Treatment. Springfield, Ill: Charles C Thomas, 1959.) B: Photograph of Fedor Krause. (Reprinted from Kolle K (ed): Grosse Nervenärtze. Stuttgart: Thieme, 1963, 199-206.)

to minimize brain retraction. His contribution eventually decreased the mortality rate of the procedure to $5 \% .{ }^{66}$ Frazier subsequently suggested the idea of subtotal sectioning of the nerve, specifically sectioning only the fasciculi of the sensory root (outer two thirds) while sparing the motor root (inner third) ${ }^{59}$ In 1921, Frazier stated:

In the past the motor root was often sacrificed because the surgeon was afraid he might be leaving a fasciculus of the sensory root with all its unfortunate possibilities. But with the use of the electrode, the motor root, when exposed, can positively be identified as motor, by observing the temporal muscle contact.... The exposure of the motor root is so easily obtained that one wonders why for so many years it was needlessly sacrificed.

Finally, in 1928, Stookey added the concept of differential sectioning of the dorsal root, which involved sectioning only those fibers within the affected division of the trigeminal

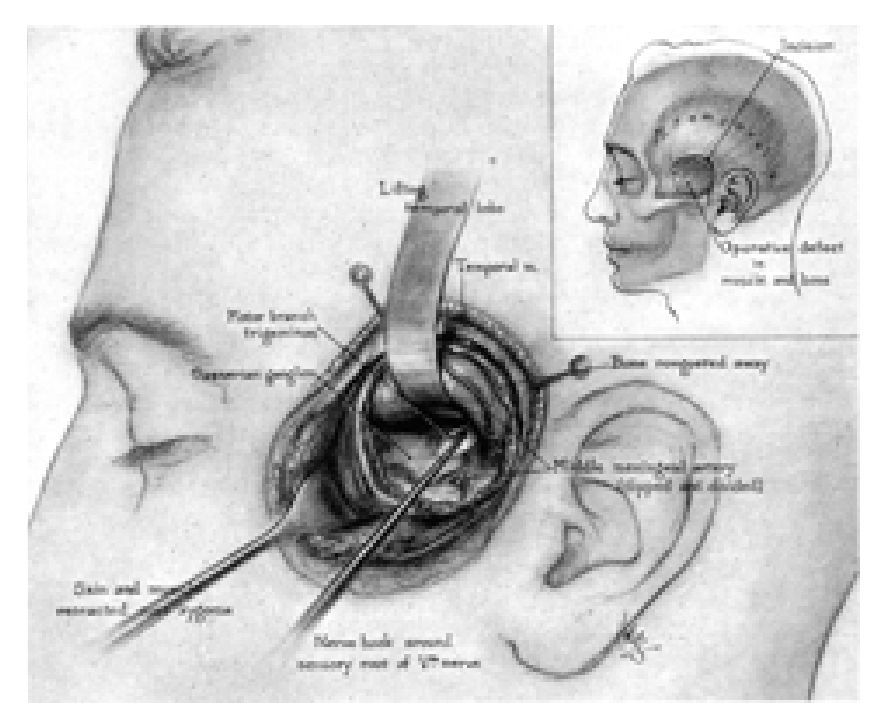

Fig. 5. Illustration of the Hartley-Krause procedure, an extradural subtemporal approach for resection of the gasserian ganglion. (Reprinted from Dandy WE: The brain, in Walters W, Ellis FH Jr (eds): Lewis-Walters Practice of Surgery. Hagerstown, MD: W.F. Prior Co., 1963, Vol XII, pp 1-671.) root, leaving intact the remaining fibers, thereby limiting the area of sensory loss. ${ }^{59}$ With all of the refinements to the Horsley and subsequent Hartley-Krause procedures, the percentage of patients who obtained relief after undergoing subtemporal retrogasserian neurotomy ranged from 95 to $99 \%$; this became the preferred form of surgical treatment for TN for more than 50 years. ${ }^{22,64}$

While Frazier and others were perfecting the subtemporal retrogasserian neurotomy, Dandy (Fig. 6) devised an alternative surgical approach for partial sectioning of the trigeminal nerve via a lateral suboccipital craniectomy (Figs. 7 and 8), also referred to as the "cerebellar approach." This approach provided exposure of the trigeminal nerve root near the pons. ${ }^{66}$ Although Dandy achieved good results with a low complication rate, he cautiously stated that one could not conclude whether his cerebellar approach was equal or superior to the Spiller-Frazier method of sectioning the trigeminal nerve. ${ }^{6,66}$

Dandy claimed, however, that his cerebellar approach was "much easier and quicker to perform than the temporal method, for the route is bloodless." (see Pinkus ${ }^{44}$ and Wilkins ${ }^{66}$ ). Dandy also noted that his approach facilitated preservation of the motor root. He stated, "... the motor root was uninjured and could be seen intact through the hiatus in the severed sensory root...." 18 Despite the advantages of Dandy's operation, his innovation was commonly rejected among neurosurgeons of the time. The Spiller-Frazier procedure remained the surgery of choice during Dandy's lifetime and for at least 15 years after his death, in part because of the political lines that had been drawn between Cushing and Dandy. $22,23,44,59,63$ The Dandy-Cushing feud produced a political climate that divided the neurosurgical community and demanded loyalty to certain persons regardless of advantages in theory or technique proposed by others. ${ }^{44} \mathrm{In}$ addition, because they were working at a time when the operating microscope was not used in neurosurgery, it may have been safer for most surgeons who did not possess Dandy's excellent vision and superior surgical skill to use the middle fossa approach.

Because he approached the trigeminal nerve through the posterior fossa, Dandy was able to make unique observations relevant to the posterior fossa anatomy. These observations would not be corroborated until the operating microscope was adopted, but they eventually would lead to a more refined surgical approach for the relief of TN. Over the course of his trigeminal nerve sectioning experience in more than 500 patients, Dandy noted vascular loops impinging on the root entry zone of the trigeminal nerve in most patients. He stated, "In many instances the nerve is grooved or bent in an angle by the artery. This I believe is the cause of tic douloureux."17 It seems that Dandy, however, did not take the next logical step in suggesting that the nerve be decompressed by transposing the vessel; rather, he continued to treat the pain with partial sectioning of the nerve. ${ }^{6}$

It was not until 1967, when Peter Jannetta (Fig. 9) became the first neurosurgeon to explore the cranial nerves within the posterior fossa by using the operating microscope, that the idea that TN was a neurovascular compression syndrome was revived and the treatment of this problem by MVD was developed. ${ }^{6,30}$ Like Dandy, Jannetta observed vascular loops compressing the root entry zone of the trigeminal nerve in patients afflicted with TN and 


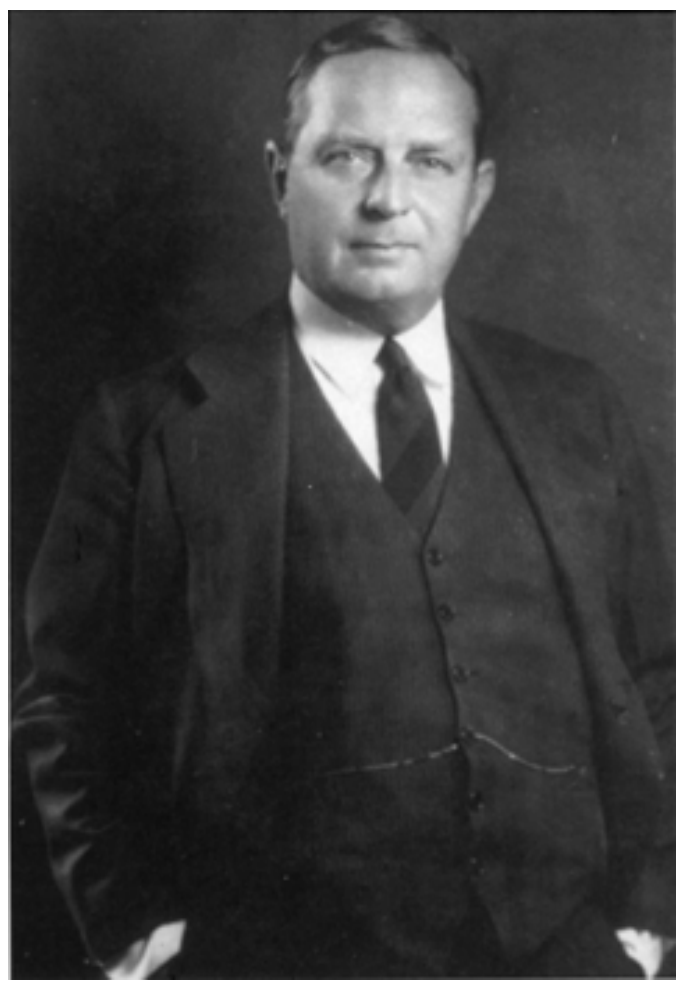

Fig. 6. Photograph of Walter Dandy. (Reprinted with permission from The Alan Mason Chesney Medical Archives of The Johns Hopkins Medical Institutions.)

believed this was likely the cause. Jannetta, however, took the next logical step and recommended decompressing the nerve by moving the offending vascular loop(s) and securing them with a small, nonabsorbent, synthetic sponge prosthesis (Fig. 10). Thus, the concept of MVD with no intentional trauma or disruption of the nerve was born. ${ }^{6}$ Jannetta subsequently extended his observations to other cranial nerves and defined other neurovascular compression syndromes, such as hemifacial spasm, that also can be treated by MVD.

Jannetta's approach was not initially accepted by most neurosurgeons, who recalled that Taarnh $\varnothing j$ 's nondestructive technique was initially successful before disappointing recurrences led to its discontinuance. In contrast, the enduringly successful outcomes for most patients treated with MVD have convinced most neurosurgeons of the validity of the concept and the treatment. ${ }^{9}$ Multiple reports confirm the results initially claimed by Jannetta, and long-term studies document the durability of the procedure. ${ }^{5,10,36}$ Successful relief of the pain of TN can be expected in approximately 95\% of patients, and long-term recurrences occur in approximately $1 \%$ per year. Today, MVD is regarded as an effective operation and the open procedure of choice for the treatment of TN. ${ }^{38}$ Jannetta deserves the credit for conceiving this method and for convincing a skeptical and, at times, hostile world of its validity.

\section{Radiation Therapy and Stereotactic Radiosurgery}

In the late $1890 \mathrm{~s}$, around the time of the initial developments in chemoneurolysis, medical, and neurectomy therapies, radiation therapy was introduced as an option for the treatment of TN. During the early developments of x-rays as a diagnostic tool, Gocht proposed radiation as a potential therapy for relieving pain in patients with breast carcinoma. ${ }^{7}$ In 1897, Gocht applied radiotherapy in the treatment of a patient with TN in whom all previous treatments had been unsuccessful. ${ }^{59}$ The patient experienced relief of pain 2 days posttreatment. Despite the early fortuitous treatment of TN with radiation therapy, however, subsequent experiments by other clinicians produced inconsistent results. ${ }^{59}$

Finally, in 1971, Leksell ${ }^{35}$ used stereotactically focused radiation to create lesions in the trigeminal ganglion and adjacent root. In 1991, Rand $^{49}$ began to treat patients in whom medical and surgical treatment of TN with a Leksell gamma knife had failed. ${ }^{66}$ Since then, many clinicians have reported on the efficacy and initial safety of gamma knife
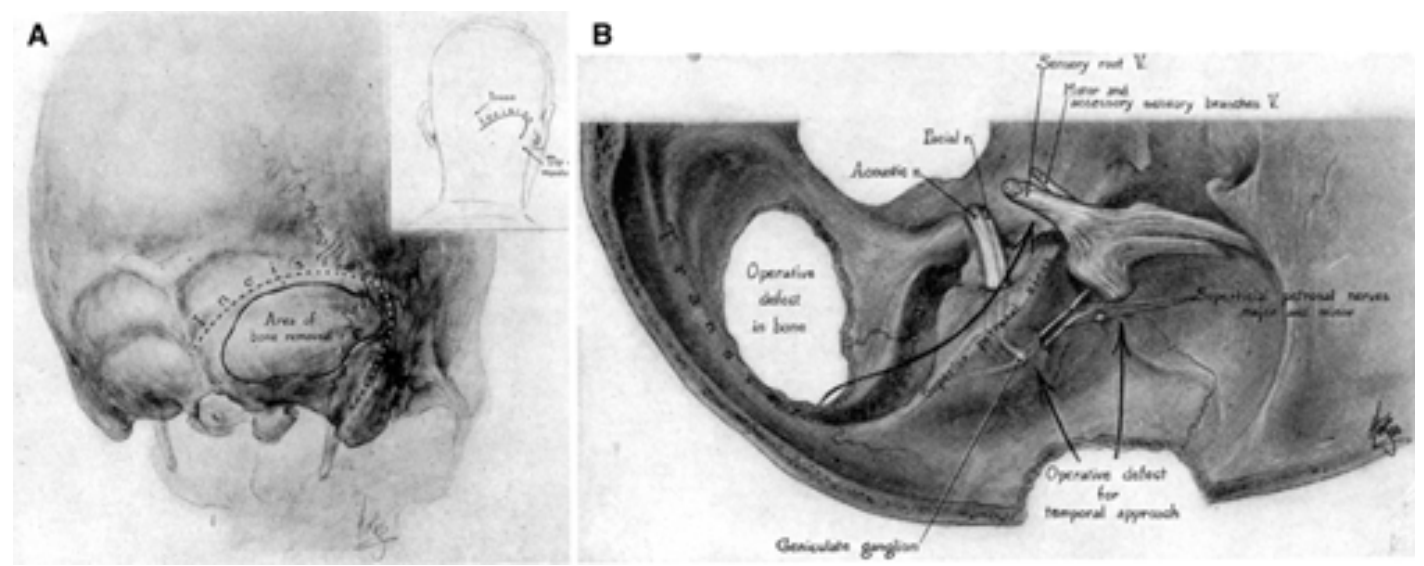

Fig. 7. A: Illustration demonstrating the incision and location of the lateral suboccipital craniectomy for Dandy's cerebellar approach to the sensory root of the trigeminal nerve. B: Drawing to compare the cerebellar and temporal routes by which the sensory root of the trigeminal nerve is reached and divided. The petrosal nerves are sketched to show their relationship to the facial nerve, which can be injured in the temporal approach. (Reprinted from Dandy WE: The brain, in Walters W, Ellis FH Jr (eds): Lewis-Walters Practice of Surgery. Hagerstown, MD: W.F. Prior Co., 1963, Vol XII, pp 1-671.) 


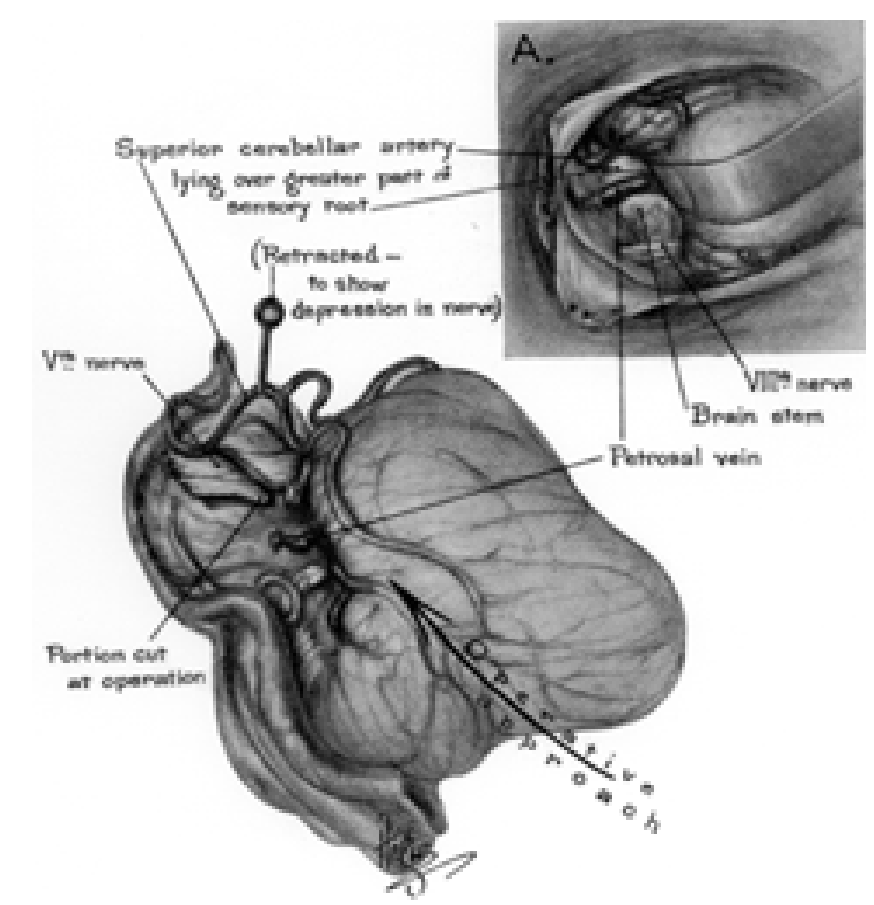

Fig. 8. Illustration of Dandy's cerebellar approach for partial trigeminal nerve section. The illustration also depicts compression of the trigeminal nerve at the root entry zone by the superior cerebellar artery, an observation that Dandy noted in most patients. $\mathrm{He}$ suggested that this vascular compression was the cause of TN. (Reprinted from Dandy WE: The brain, in Walters W, Ellis FH Jr (eds): Lewis-Walters Practice of Surgery. Hagerstown, MD: W.F. Prior Co., 1963, Vol XII, pp 1-671.)

stereotactic radiosurgery for TN..$^{33,69}$ The target has changed from the ganglion to the preganglionic root in the posterior fossa adjacent to the brainstem, which is the same area in which vascular compression is found. Concern remains about the time it takes for the treatment to achieve an effect. The completeness of relief afforded by irradia-

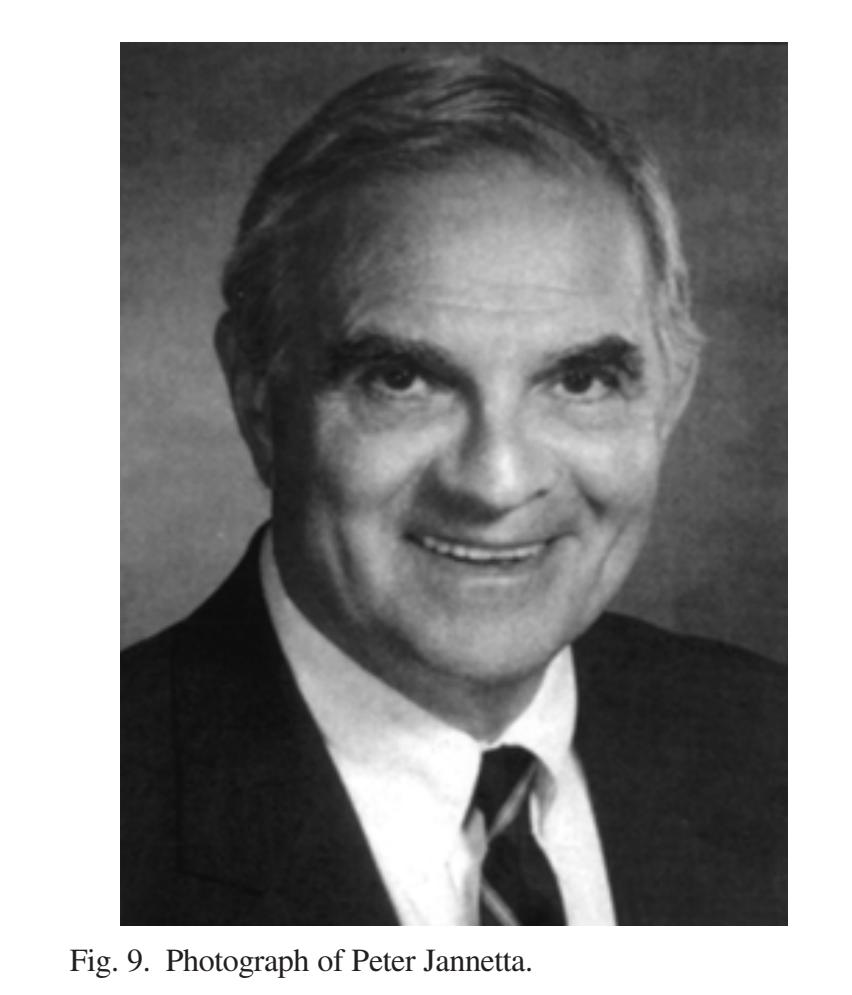

tion and possible long-term consequences of this treatment also await further investigation. ${ }^{45,46}$ For patients in whom an open or needle procedure would carry high risk, such as those with bleeding dyscrasias, stereotactic radiosurgery may be the procedure of choice.

\section{Current Treatment Options for TN}

Although the exact origin of TN remains elusive, the unique nature of the symptoms and inciting events of this disease have led to the development of numerous treatment modalities over the years. Despite uncertainty about the ex-
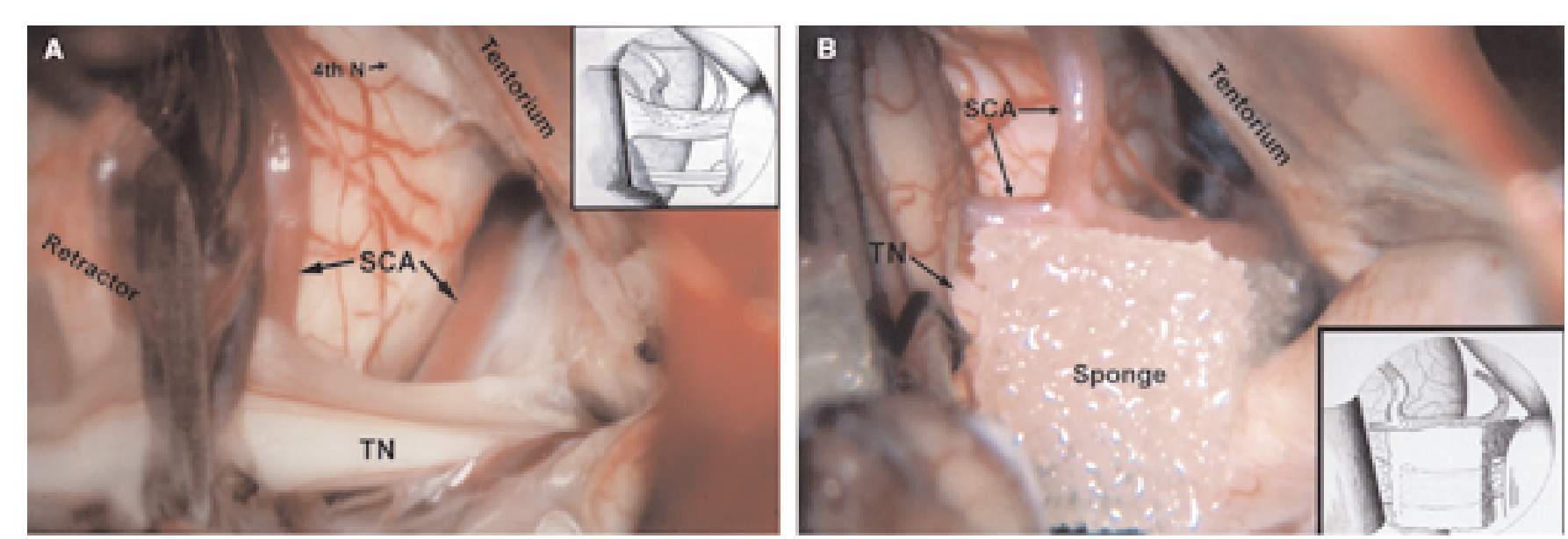

Fig. 10. A: Intraoperative photograph showing an elongated loop of superior cerebellar artery (SCA) compressing the trigeminal nerve (TN) at the root entry zone. This is also diagrammed in the inset. B: An Ivalon prosthesis has been inserted between the artery and nerve. It sits as a saddle over the nerve to secure it in place. Note the redirection of the artery to a horizontal course, which is again diagrammed in the inset. (Reprinted with permission from Liu JK, Apfelbaum RI: Treatment of trigeminal neuralgia. Neurosurg Clin N Am 15:319-334, 2004.) 
act pathophysiology, it is clear that root entry zone segmental demyelination is a common denominator in most, if not all, cases. Multiple sclerosis causes such demyelination and causes 1 to $3 \%$ of the cases of TN. Vascular compression causes similar demyelination, again affecting the centrally myelinated fibers extending into the nerve at the root entry zone (Obersteiner-Redlich zone). The other recognized cause of TN is a mass lesion compressing the nerve. These lesions are located in the same area and likely cause similar internal derangement in the nerve. Some abnormal circuitry appears to result from this demyelination, which results in nonnoxious stimuli provoking paroxysms of intense pain. Peripheral denervation, decompressing the site of compression, or using nonanalgesic medications that affect nerve conduction and hence likely alter the timing in the deranged circuits have been beneficial for these patients.

The goal of treatment in patients suffering from this excruciating pain must be complete pain relief at an acceptable level of side effects. The patient should be free of pain as well as of the fear of its recurrence. Medical therapy is the initial treatment of choice. When medical treatment fails or is limited by significant side effects, surgical treatment options with excellent success rates are available. The best surgical treatment for a particular patient depends on the individual's medical comorbidities, on the risks he or she is willing to assume, and, to a lesser extent, on the patient's age. The Jannetta MVD appears to be the best choice for younger $(<65-70$ years old), healthy patients with longer life expectancy because it avoids intentional neural damage while achieving excellent durable relief of their pain. It can be used in older patients as well if they are willing to accept the slightly higher risks of the procedure. Percutaneous trigeminal neurolysis is a useful minimally invasive approach that, while intentionally destructive, endeavors to produce an incomplete lesion that often spares some trigeminal function. It probably should be the procedure of choice for older patients, for those with significant medical comorbidities, and for patients with multiple sclerosis. ${ }^{38}$ Partial nerve sectioning as recommended by Dandy may be considered in patients in whom explorations during an MVD have yielded negative findings, or when other less invasive procedures have failed. Finally, the role of stereotactic radiosurgery in the treatment of TN is currently being defined.

\section{References}

1. Ameli NO: Avicenna and trigeminal neuralgia. J Neurol Sci 2: 105-107, 1965

2. André N: Observations Pratiques sur Les Maladies de l'urèthre et sur Plusieurs Faits Convulsifs, \& la Guérison de Plusieurs Maladies Chirurgicales, Avec La Decomposition d'un Remède Proper à Réprimer la Dissolution Gangréneuse \& Concéreuse, \& á la Réparer; Avec Des Principes Qui Pourront Server à Employer les Differens Caustiques. Paris: Delaguette, 1756

3. Apfelbaum R: Trigeminal and glossopharyngeal neuralgia and hemifacial spasm, in Grossman RG, Loftus CM (eds): Principles of Neurosurgery, ed 2. Philadelphia: Lippincott-Raven, 1999, pp 407-419

4. Apfelbaum R: Trigeminal rhizotomy, in Burchiel K (ed): Surgical management of pain. New York: Thieme, 2002, pp 898-902
5. Apfelbaum RI: A comparison of percutaneous radiofrequency trigeminal neurolysis and microvascular decompression of the trigeminal nerve for the treatment of tic douloureux. Neurosurgery $1: 16-21,1977$

6. Apfelbaum RI: Neurovascular decompression: the procedure of choice? Clin Neurosurg 46:473-498, 2000

7. Artico M, De Caro GM, Fraioli B, et al: 1897—celebrating the centennial-Hermann Moritz Gocht and radiation therapy in the treatment of trigeminal neuralgia. Acta Neurochir 139: 761-763, 1997

8. Baker KA, Taylor JW, Lilly GE: Treatment of trigeminal neuralgia: use of baclofen in combination with carbamazepine. Clin Pharm 4:93-96, 1985

9. Barker FG II, Jannetta PJ, Bisonette DJ, et al: The long-term outcome of microvascular decompression for trigeminal neuralgia. N Engl J Med 334:1077-1083, 1996

10. Bederson JB, Wilson CB: Evaluation of microvascular decompression and partial sensory rhizotomy in 252 cases of trigeminal neuralgia. J Neurosurg 71:359-367, 1989

11. Bergouignan M: Cures heureuses de neurologies essentielles par le dephenyl hydantoinate de sounde. Rev Laryngol Otol Rhinol 63:34-41, 1942

12. Blom S: Trigeminal neuralgia: its treatment with a new anticonvulsant drug (G-32883). Lancet 1:839-840, 1962

13. Brown JA, Chittum CJ, Sabol D, et al: Percutaneous balloon compression of the trigeminal nerve for treatment of trigeminal neuralgia. Neurosurg Focus 1(2):E4, 1996

14. Brown JA, Coursaget C, Preul MC, et al: Mercury water and cauterizing stones: Nicolas Andre and tic douloureux. J Neurosurg 90:977-981, 1999

15. Court JE, Kase CS: Treatment of tic douloureux with a new anticonvulsant (clonazepam). J Neurol Neurosurg Psychiatry 39:297-299, 1976

16. Cushing H: A method of total extirpation of the gasserian ganglion for trigeminal neuralgia. By a route through the temporal fossa and beneath the middle meningeal artery. JAMA 34: 1035-1041, 1900

17. Dandy WE: The brain, in Walters W, Ellis FHJ (eds): LewisWalters' Practice of Surgery. Hagerstown, MD: WF Prior, 1963, Vol XII, pp 1-671

18. Dandy WE: Section of the sensory root of the trigeminal nerve at the pons: preliminary report of the operative procedure. Bull Johns Hopkins Hosp 36:105-106, 1925

19. Dewhurst K: A symposium on trigeminal neuralgia: with contributions by Locke, Syndenham, and other eminent seventeenth century physicians. J Hist Med Allied Sci 12:21-36, 1957

20. Fothergill J: Of a painful affection of the face, in Society of Physicians in London: Medical Observations and Inquiries. London: T Cadell, 1773, Vol 5 pp 129-142

21. Fromm GH, Terrence CF, Chattha AS: Baclofen in the treatment of trigeminal neuralgia: double-blind study and long-term follow-up. Ann Neurol 15:240-244, 1984

22. Gardner WJ: Concerning the mechanism of trigeminal neuralgia and hemifacial spasm. J Neurosurg 19:947-958, 1962

23. Gardner WJ, Miklos MV: Response of trigeminal neuralgia to decompression of sensory root; discussion of cause of trigeminal neuralgia. JAMA 170:1773-1776, 1959

24. Häkanson S: Trigeminal neuralgia treated by the injection of glycerol into the trigeminal cistern. Neurosurgery 9:638-646, 1981

25. Harris W: An analysis of 1, 433 cases of paroxysmal trigeminal neuralgia (trigeminal-tic) and the end-results of gasserian alcohol injection. Brain 63:209-224, 1940

26. Härtel F: Über die intracranielle Injektionsbehandlung der Trigeminusneuralgie. Med Klinik 10:582-584, 1914

27. Hartley F: Intracranial neurectomy of the second and third divisions of the fifth nerve; a new method. NY Med J 55:317-319, 1892

28. Horsley V, Taylor J, Coleman WS: Remarks on the various surgical procedures devised for the relief or cure of trigeminal neu- 
ralgia (tic douloureux). Br Med J 2:1139-1143, 1191-1193, 1249-1252, 1891

29. Hutchinson B: Cases of Tic Douloureux Successfully Treated. London: Longmans, 1820

30. Jannetta PJ: Arterial compression of the trigeminal nerve at the pons in patients with trigeminal neuralgia. J Neurosurg 26 (Suppl):159-162, 1967

31. King RB: The value of mephenesin carbamate in the control of pain in patients with tic douloureux. J Neurosurg 25:153-158, 1966

32. Kirschner M: Zur Elektrochirurgie. Arch Klin Chir 167: 761-768, 1931

33. Kondziolka D, Lunsford LD, Flickinger JC, et al: Stereotactic radiosurgery for trigeminal neuralgia: a multi-institutional study using the gamma unit. J Neurosurg 84:940-945, 1996

34. Krause F: Resection des Trigeminus innerhalb der Schadelhohle. Arch Klin Chir 44:821-832, 1892

35. Leksell L: Stereotaxic radiosurgery in trigeminal neuralgia. Acta Chir Scand 137:311-314, 1971

36. Levy EI, Jannetta PJ: Microvascular decompression, in Burchiel K (ed): Surgical Management of Pain. New York: Thieme, 2002, pp 878-888

37. Lewy F: The first authentic case of major trigeminal neuralgia and some comments on the history of the disease. Ann Med Hist 10:247-250, 1938

38. Liu JK, Apfelbaum RI: Treatment of trigeminal neuralgia. Neurosurg Clin N Am 15:319-334, 2004

39. Lunsford LD, Apfelbaum RI: Choice of surgical therapeutic modalities for treatment of trigeminal neuralgia: microvascular decompression, percutaneous retrogasserian thermal, or glycerol rhizotomy. Clin Neurosurg 32:319-333, 1985

40. Mullan S, Lichtor T: Percutaneous microcompression of the trigeminal ganglion for trigeminal neuralgia. J Neurosurg 59: 1007-1012, 1983

41. Napier LE, Sen Gupta PC: A peculiar neurological sequel to administration of 4:4'-diamidino-diphenyl-ethylene (M \& B 744). Indian M Gaz 77:71-74, 1942

42. Nugent GR: Radiofrequency treatment of trigeminal neuralgia using a cordotomy-type electrode. A method. Neursurg Clin N Am 8:41-52, 1997

43. Pearce JM: Trigeminal neuralgia (Fothergill's disease) in the 17 th and 18th centuries. J Neurol Neurosurg Psychiatry 74: 1688,2003

44. Pinkus RL: Innovation in neurosurgery: Walter Dandy in his day. Neurosurgery 14:623-631, 1984

45. Pollock BE, Foote RL, Link MJ, et al: Repeat radiosurgery for idiopathic trigeminal neuralgia. Int J Radiat Oncol Biol Phys 61:192-195, 2005

46. Pollock BE, Phuong LK, Foote RL, et al: High-dose trigeminal neuralgia radiosurgery associated with increased risk of trigeminal nerve dysfunction. Neurosurgery 49:58-64, 2001

47. Pollock LJ, Potter HE: Experimental studies of injection of the gasserian ganglion controlled by fluoroscopy. JAMA 67: 1357-1361, 1916

48. Putnam TJ, Hampton AO: A technic of injection into the gasserian ganglion under roentgenographic control. Arch Neurol Psychiat 35:92-98, 1936

49. Rand RW: Leksell Gamma Knife treatment of tic douloureux. Neurosurg Clin N Am 8:75-78, 1997

50. Rose FC: European neurology from its beginnings until the 15th century: an overview. J Hist Neurosci 2:21-44, 1993
C. D. Cole, J. K. Liu, and R. I. Apfelbaum

51. Rose FC: The neurology of ancient Greece-an overview. J Hist Neurosci 3:237-260, 1994

52. Rose FC: Trigeminal neuralgia. Arch Neurol 56:1163-1164, 1999

53. Rose W: Removal of the gasserian ganglion for severe neuralgia. Lancet 2:914-915, 1890

54. Rosegay H: The Krause operations. J Neurosurg 76:1032-1036, 1992

55. Rovit RL: Percutaneous radiofrequency thermal coagulation of the gasserian ganglion, in Rovit RL, Murali R, Jannetta PJ (eds): Trigeminal Neuralgia. Baltimore: Williams \& Wilkins, 1990, pp 109-136

56. Rushton JG: Trigeminal neuralgia; one hundred fifty years of nonsurgical treatment. Minn Med 40:702-706, 1957

57. Shelden CH, Pudenz RH, Freshwater DB, et al: Compression rather than decompression for trigeminal neuralgia. J Neurosurg 12:123-126, 1955

58. Sist T, Filadora V, Miner M, et al: Gabapentin for idiopathic trigeminal neuralgia: report of two cases. Neurology 48:1467, 1997

59. Stookey B, Ransohoff J: Trigeminal Neuralgia: Its History and Treatment. Springfield, IL: Charles C. Thomas, 1959

60. Sweet WH, Wepsic JG: Controlled thermocoagulation of trigeminal ganglion and rootlets for differential destruction of pain fibers. 1. Trigeminal neuralgia. J Neurosurg 40:143-156, 1974

61. Taarnhøj P: Decompression of the trigeminal root and the posterior part of the ganglion as a treatment in trigeminal neuralgia; preliminary communication. J Neurosurg 9:288-290, 1952

62. Tew JM Jr, Taha JM: Percutaneous rhizotomy in the treatment of intractable facial pain (trigeminal, glossopharyngeal, and vagal nerves), in Schmidek HH, Sweet WH (eds): Operative Neurosurgical Techniques: Indications, Methods and Results, ed 3. Philadelphia: WB Saunders, 1996

63. Wangensteen $\mathrm{OH}$, Wangensteen SD: The Rise of Surgery: From Emperic Craft to Scientific Discipline. Minneapolis: University of Minnesota, 1978

64. White JC, Sweet WH: Pain and the Neurosurgeon: A FortyYear Experience. Springfield, IL: Charles C Thomas, 1969

65. Wilkins RH: Historical perspectives, in Rovit RL, Murali R, Jannetta PJ (eds): Trigeminal Neuralgia. Baltimore: Williams \& Wilkins, 1990, pp 1-25

66. Wilkins RH: Trigeminal neuralgia: historical overview, with emphasis on surgical treatment, in Burchiel K (ed): Surgical Management of Pain. New York: Thieme, 2002, pp 288-301

67. Wilkins RH, Brody IA: Bell's palsy and Bell's phenomenon. Arch Neurol 21:661-662, 1969

68. Woodhall B, Odom GL: Stilbamidine isethionate therapy of tic douloureux. J Neurosurg 12:495-500, 1955

69. Young RF, Vermeulen SS, Grimm P, et al: Gamma Knife radiosurgery for treatment of trigeminal neuralgia: idiopathic and tumor related. Neurology 48:608-614, 1997

Manuscript received March 15, 2005.

Accepted in final form April 8, 2005.

Address reprint requests to: Ronald I. Apfelbaum, M.D., Department of Neurosurgery, University of Utah, 30 North 1900 East, Suite 3B409, Salt Lake City, Utah 84132. email: ronald.apfelbaum @hsc.utah.edu. 